\title{
Defining the Social Enterprise: A Tangled Web
}

\author{
Katherine Isabel Rostron \\ University of Salford, United Kingdom
}

\begin{abstract}
This paper aims to inform those reviewing the literature defining the social enterprise. The researcher made observations as part of a wider review of the Social Enterprise literature. The review was undertaken by searching with a range of key words, targeting relevant journals to identify relevant papers and used citations and references to search for further relevant material. The discussion has a UK perspective and consults but does not comprehensively incorporate the international literature. The findings include the discovery that while a definition may remain elusive the process of searching provides opportunities to deepen understanding of the topic. The author recommends further research to explore the perspectives of users, employees and managers of social enterprises to add to the discussion that already exists amongst the academics and policy makers.
\end{abstract}

Paper Type: Conceptual Paper

Keywords: Social Enterprise, Definition, Contextual Meaning 


\section{Introduction}

The lines between the commercial and social economy are blurring. Organisations in the private sector are encouraged to adopt business practices and improve efficiency and private sector businesses are becoming more sensitive to their own social impact (Defourny, 2014; Porter and Kramer, 2011). Social enterprises (SEs) are businesses which inhabit the space between the public and private sectors.

Definitions of SEs will invariably describe a business with 'social objectives'. Despite this apparently simple defining feature the debate surrounding the term 'social enterprise' is a distinguishing feature of the academic research about SEs (Dart, 2004; Zahra et al, 2008; Peattie and Morley, 2008; Doherty et al., 2009; Galera and Borzaga, 2009; Kerlin, 2010; Defourny and Nyssens, 2014). 'Social enterprise means different things to different people across different contexts. Its meanings are culturally, economically, socially historically and politically variable' (Kerlin, 2010). As a policy maker, teacher, researcher in the area of SEs you may be obliged to engage in the task of untangling the discussion surrounding the definition of an SE. The process of 'untangling' reveals that as well as disagreements about how to define SEs there is a lack of clarity in the way we describe the landscape of the social enterprise and how SEs are positioned within it.

This article identifies relevant points for discussion with the aim of making the path through this tangled web a little easier. The review involved the following search activities; using a range of search terms aimed at identifying relevant literature, targeting relevant journals and searching the article titles within them and finally using the citations and references to search forward and backwards for further relevant material. The review has a UK perspective and so focuses on two definitions one from the UK government and one from EU funded research. This paper consults, but does not comprehensively incorporate, the international literature.

\section{Does a definition matter?}

The advantages of a lack of agreement in defining SEs are acknowledged in the literature. Ambiguity encourages continual rethinking in the field (Galera and Borzaga, 2009), and encourages and allows for diversity (Jones and Keogh, 2006). However, the review found that the dominant view in the literature is that a consistent and effective definition is desirable.

Pearce (2003) regards a clear and unambiguous understanding of what a social enterprise is as necessary for two reasons; firstly to establish their unique selling point, by which Pearce refers to their values which will help avoid being absorbed as a subset of the private or public system and secondly for the purposes of ruling out what is not a social enterprise where there may be certain benefits/incentives offered to SEs (Pearce, 2003). According to Teasedale, et al. (2013) the lack of clarity in the definition of what an SE actually is has allowed the UK government to use its various and varied attributes to conceal the pretext for its use, in this case a pervasive belief in market systems.

International Journal of Management and Applied Research, 2015, Vol. 2, No. 2 
Jones and Keogh (2006) call for precision and clarity and a need to be able to define in order to '...measure, compare and critically assess...success...' in order to be able to communicate added value as a 'sector'. Supporting this view is a belief that the confusion in defining SEs is a contributing factor to the limitations and paucity of research in this area (Bull and Crompton, 2006; Peattie and Morley, 2008; Zahra et al, 2008; Gordon, 2012).

\section{Social Enterprise or Social Entrepreneurship?}

Galera and Borzaga (2010) describe social entrepreneurship as an umbrella term describing a set of initiatives and social trends and its literature being characterised by a focus on the individual. SEs are then a facet of social entrepreneurship. However there is little consistency across the literature. Mikami's (2014) article 'An alternative framework for the analysis of social enterprises' builds on the work of Peredo and McLean (2006) titled 'Social Entrepreneurship: A critical review of the concept'. This is an example from the literature between the two terms being used interchangeably even where the purpose of the article is directly related to defining the term in order to effectively analyse.

Peredo (2006) does in fact address the words used stating that social entrepreneurship and social enterprise (as in an activity) are used 'commonly equated' and used 'interchangeably' and confirms that this interchangeability will be applicable to his article. Peredo (2006) goes on to make a further distinction of social enterprises, conceding that the relationship between social enterprises and social entrepreneurship is more complex and leaving this at '...an intuitive level for purposes of this paper.' Mikami (2014) in his discussion of SEs does not address this complexity and in doing so add confusion to the ideas presented.

The potential for confusion in the use of the term 'social enterprise' as a verb i.e. to engage in social enterprise and the term 'social enterprise' as a noun i.e. to manage a social enterprise is also apparent in the literature. Sometimes the distinction is made explicit, e.g. social enterprise as an activity or social enterprise as an entity (Thompson, 2011) which is helpful. For clarity, in this article we are referring social enterprise (noun) as an organisation rather than an activity.

\section{Problems defining SEs}

The review finds that the major point of disagreement hinges on whether a definition of SEs should include characteristics such as democratic decision making, decentralisation and a participatory approach to governance (Defourny and Nyssens, 2014; Pearce, 2003) or adopt a more succinct and potentially looser definition simply to authenticity as a business and social objectives (DTI, 2002).

Additional factors for ongoing debate about definitions for the term 'social enterprise' are also identified in the literature:

1. Diversity of SE organisations (Pearce, 2003; Jones and Keogh, 2006; Defourny and Nyssens, 2014); 
2. A diverse conception of SEs internationally (Defourny and Nyssens, 2014; Defourny and Kim, 2011);

3. Absence of a single legal form for SEs (IFF Research 2005);

4. The variety of ways they seek income including mixing profit and non-profit making activities (Jones and Keogh, 2006);

5. Interchangeable and changing use of terms in academia and in the field e.g. social entrepreneur, social entrepreneurship , community enterprise and social enterprise (Defourny and Kim, 2008; Jones and Keogh, 2006);

6. The fast paced growth of the literature (Defourny and Kim, 2011);

7. Fast pace of growth and evolution of SEs and their environment (Defourny, 2014; Jones and Keogh, 2006).

A useful starting point for considering the definition of SEs is to consider the space they occupy between the public and private sectors, '...in most ways like any other private sector businesses, but are geared toward social regeneration and help rather than simply the generation of profits... as such social enterprises do not fall within the standard definition of private or public sector enterprises' (HM Treasury, 1999). Two widely used definitions of SEs have emerged; the EMES definition first published in 2001 (Borzaga and Defourny, 2001) and the definition first used in the UK Governments' Department of Trade and Industry (DTI) 2002 paper, 'Social Enterprise: A Strategy for Success' (DTI, 2002).

\section{The UK definition of a social enterprise}

The UK definition originated in the UK Government document 'A Progress Report on Social Enterprise: A strategy for success' which reported on the progress of its new SE strategy (DTI, 2002). The report defines an SE as '.... business with primarily social objectives whose surpluses are principally reinvested for that purpose in that business or in the community, rather than being driven by the need to maximise profit for shareholders and owners' (DTI, 2002). The definition was a result of a consultation process with sector leaders and facilitated by the DTI (DTI, 2002).

UK government reports and several researchers in the field use this definition in research (IFF Research, 2005). This definition is considered to be the one most widely used in the UK (Doherty et al., 2009). Jones and Keogh (2006) describe this definition as distinct to others in its insistence of the social enterprise as a business.

A report commissioned by the UK government's Social Enterprise Unit in 2003 synthesised research undertaken using the Department of Trade and Industry's 2002 definition and identified numerous challenges with consistency and comparability (Ecotec, 2003). The definition has been identified as being intentionally 'broad' making 'this commonly accepted definition ... hard to put into practice' (Lyon et al, 2010).

Discussion relating to the operational challenges of the DTI's 2002 definition has continued (Lyon et al. 2010; Defourny et al, 2014). Lyon et al (2010) examine four government studies and identify the challenges of using the definitions. Lyon et al (2010) identifies numerous instances of ambiguity in the defining of SEs using the

International Journal of Management and Applied Research, 2015, Vol. 2, No. 2 
DTI's 2002 definition which make mapping SEs and providing an evidence base problematic.

Lyon's key critique is that although the definition may be useful for policy purposes it is not adequate for research and secondly that in the research there is not enough information, discussion and methodological interrogation of the sample in relation to the definition and the data sources (Lyon, et al. 2010). A further indication of confusion with the definition is the significant number of business identifying themselves as SEs but not identified as such by the definition applied in government funded research and vice versa (IFF, 2005).

\section{The EMES definition of SEs}

The EMES is an international research network that emerged from a large EU funded European research project on SEs in the 1990s. EMES is led by Professor of Third Sector Economics and Social Enterprise at the University of Liege, Jacques Defourny. The EMES International Research Network coordinates large scale collaborative international social enterprise research (EMES, 2015).

The EMES definition was the result of a four year project and comes in the form of indicators rather than a definitive definition. The EMES dimensions are intended to be capable of 'encompassing national differences' (Galera and Borzoga, 2009). The EMES conceptual framework is based on three broad categories, which include the economic, organisational and entrepreneurial dimensions of SEs, see below:

1. Economic and entrepreneurial dimensions of SEs;

a) A continuous activity producing goods and /or selling services

b) A significant level of economic risk

c) A minimum amount of paid work

2. Social dimensions of SEs;

d) An explicit aim to benefit the community

e) An initiative launched by a group of citizens or civil society organisations

f) A limited profit distribution

3. Participatory governance of social enterprise;

g) A high degree of autonomy

h) A decision-making power not based on capital ownership

i) A participatory nature, which involves various parties affected by the activity Source: Defourny (2014: 26-27)

The EMES approach reflects the diversity of SEs but fails to provide a concise definition. Instead its strength is in its construction of a series of indicators through an extensive and systematic process in numerous research projects. The EMES indicators are proposed to help to identify and describe SEs without being prescriptive. These indicators aim to represent the ideal SE. In addition the EFES approach places a greater emphasis on the democratic control (governance) of SEs than the UK definition, 
Businesses need not possess all the indicators to be defined as SEs and so it is questionable how helpful they would be in a situation where SEs needed to be screened in/out for the purposes of tax relief or indeed for a research project sample. The EMES indicators may have more use as a tool, as Defourny describes, researchers can use the indicators to orientate individual businesses within a wider 'galaxy' (Defourny et al, 2014).

The EMES indicators are the result of a more careful construction that the DTI's 2002 definition and this are evident as the indicators address the whole of the business. The inclusion of the organisational characteristics expected to be present in a social enterprise such as a shared autonomy, decision making structure, presence of a participatory nature and add an additional dimension by which to decide whether a business is a social enterprise or not. So while the EMES indicators ultimately rely on personal judgement when deciding what is or are not an SE they provide a more detailed account of what a social enterprise may look like.

\section{Social enterprise as a construct in the UK}

Any discussion about the origins and definitions of SEs should acknowledge the role played by politics and policy in a given context (EMES, 2015). In the UK the term 'social enterprise' at one time referred to organisations which engaged in trade and brought about social change outside the traditional commercial sector and independently of government. At that time businesses which fit these credentials were community enterprises (businesses with a geographically centred social aim) and cooperatives, these were grouped under a term that had not been used before by the UK government, 'social enterprise' (Pearce, 2003). So for the UK government an SE could be described as organisations with a social aim, that make a profit through trade in goods or services and that may or may not rely on funding (Teasedale, 2010).

From the late 1990s SEs were adopted by New Labour and 'reframed' as a vehicle for achieving a range of policy objectives (Somers, 2013). Teasedale (2010) brings together perspectives from individuals involved in the working groups set up to inform the DTI's Social Enterprise Unit strategy. The working groups involved representatives from three organisational types; cooperatives, community businesses and social businesses. According to Teasdale's (2010) research three perspectives can be identified, which caused an element of disagreement in the working groups. These disagreements are relevant to the ongoing discussion about the definition of an SE. The representative of the cooperatives were keen to preserve the notion of economic democracy, the representatives of the community enterprises were keen to recognise that they may never be wholly sustainable and representatives of the social businesses promoted the idea that SEs are mainstream businesses with a social or environmental purpose.

We can trace the changes in meaning of the term social enterprise in the period that follows. Teasedale (2010) describes the period from 1999-2001 as including intense lobbying by these competing interest with the cooperatives and community enterprises having most influence. Teasedale identifies a shift in the 'central core' the meaning of the term social enterprise between 2001 and 2005 away from SEs as a

International Journal of Management and Applied Research, 2015, Vol. 2, No. 2 
vehicle for regeneration and towards them being largely like any other business, '...a broadening of the social enterprise construct'. And thus Teasedale (2010) identifies stages in the development of the term social enterprise first used to combine cooperatives and community businesses, later to include social businesses and still later to include organisations in the third sector.

\section{The landscape of the social enterprise}

An understanding of SEs requires an initial examination of the way we define the environment they operate within. This examination reveals further complexity and ambiguity. The third sector can be understood to refer to include the voluntary organisations, the informal family economy and social enterprises (Pearce, 2003). The third sector sits alongside the private sector (commercial, profit making businesses) and the public sector (the planned non-trading provision of services via government and other public organisations). According to Defourny (2014) the term third sector emerged in the 1990s and has since been acknowledged internationally. The literature fails to support this universal acknowledgement and it is described as one of many terms that fail to be consistently understood and adequate (Jones and Keogh, 2006). The review revealed even less international agreement about the parts that make up the third sector.

It is helpful to acknowledge differences between the US and Europe. The terms 'nonprofit' and 'not-for-profit' are used to describe organisations and the activities they undertake in the 'not-for-profit' sector in the US (Defourny, 2014). Jones and Keogh (2006) identify the limitations of this specific terminology. The construction of a 'sector' on the basis of 'profit' or 'non-profit' is not compatible with the emerging models within relevant organisations (Jones and Keogh 2006). Organisations may undertake profit making activities to fund/support a social or environmental cause e.g. a charity or operate a commercial model and reinvest a proportion of profits but principally exist to pursue a social or environmental aim (a social enterprise). The 'non-profit'/'not-for-profit' terminology may be inadequate to describe and encompass the activities and emerging business models of organisations operating in the third sector. The discussion of Jones and Keogh (2006) raises the issues of the concept of 'profit' and SEs but is not discussed further here.

In Europe the evolution of terminology has been more disparate, but the term social economy has emerged and is recognised and used by the European Union's institutions (European Social and Economic Committee, 2007). According to some sources the social economy refers to the parts of the third sector that participate in trade encompassing co-operatives, mutual societies, associations, social enterprises and foundations (Pearce, 2003; Defourny, 2014). This understanding of 'social economy' sees it as distinct from the concept of the 'not-for-profit'.

Jones and Keogh (2006) illustrate that a universal acceptance of what the social economy is has not been achieved. They describe the social economy as having 'different meanings depending on the organisations or activity you have in mind'. They also describe one meaning as broad and vague and encompassing everything outside than the public and private sector (Jones and Keogh, 2006). A limitation of

International Journal of Management and Applied Research, 2015, Vol. 2, No. 2 
their discussion is that they do not go on to identify other descriptions of the social economy or provide sources for the discussion.

\section{Positioning Social Enterprise}

Part of the discussion about what an SE is addresses 'how' SEs are positioned in the wider economic context. Pestoff, (1992) a Swedish political scientist, promotes third sector solutions as an alternative to privatisation of social welfare in Sweden. Pestoff did not use the term 'social enterprise' and presents cooperatives as an option providing social welfare. Pestoff provides a useful starting point for discussion about the characteristics and function of the 'third sector' and the boundaries between it and the other parts of the economy.

Pestoff's (1992) Welfare Mix model introduces the use of distinctions based on the private/public, formal/informal and for-profit/not for-profit attributes of organisations and then demonstrates (with the use of the over-lapping circle) that organisations in the third sector can transcend these boundaries. The accompanying discussion describes how new 'untraditional...economically feasible' third sector organisations can use the advantages of the state, community and market sector to provide superior welfare provision.

Pestoff (1992) proposes that 'producers and consumers can be bought together in untraditional forms'. When we revisit Pestoff's proposals and the Welfare mix model (see figure 1), it can be noted that social enterprise has since emerged as such an untraditional form of third sector organisation. Pestoff (1992) identifies the advantages of delivering social welfare via a worker cooperative over a public or nonprofit organisation based on its commercial characteristics i.e. it operates in the market and offers the consumer power to exit and exercise choice.

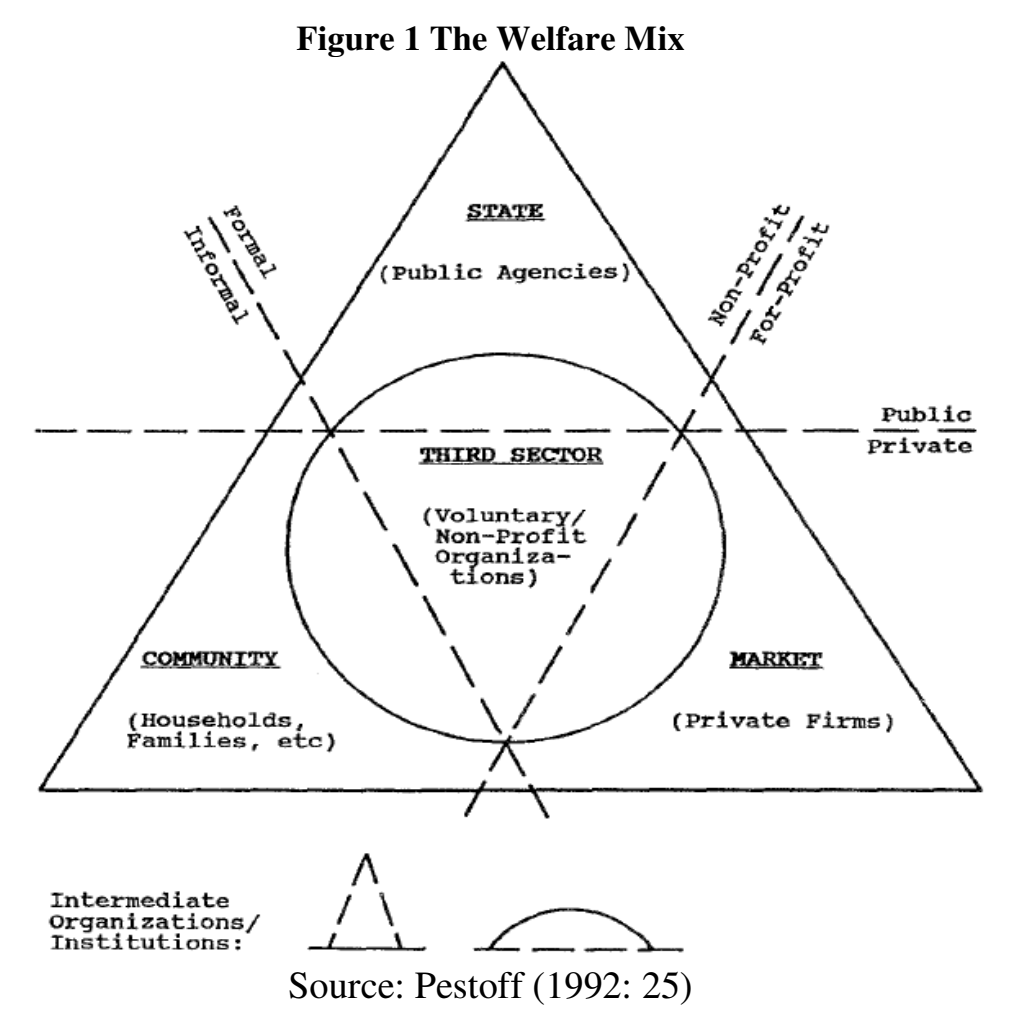

International Journal of Management and Applied Research, 2015, Vol. 2, No. 2 
Pestoff's Welfare Mix model positions the third sector alongside other parts of the economy and illustrates the relationships between them. Pestoff's objective is to show that there are alternatives to public non-profit and private for-profit solutions, which include the private non-profit organisations of the third sector. Pestoff's model provides distinctions between the private non-profit organisations, the state, private firms operating in the market and a 'community' sector. Private non-profit organisations are located in the third sector and are distinct from public sector organisations because they do not depend on public funding, are distinct from the private sector organisations by their non-profit motivations and from community organisations by their formality (Pestoff, 1992).

A decade later, Pearce (2003) presents the Three Systems Model (see figure 2) with the aim of positioning the social economy and SEs within it. The Three Systems Model made up of the public economy of planned provision, the private economy of profit orientated businesses and the third economy of social enterprise, voluntary organisations and the family economy. The systems are presented around concentric circles which subdivide into levels of the economy from local to international.

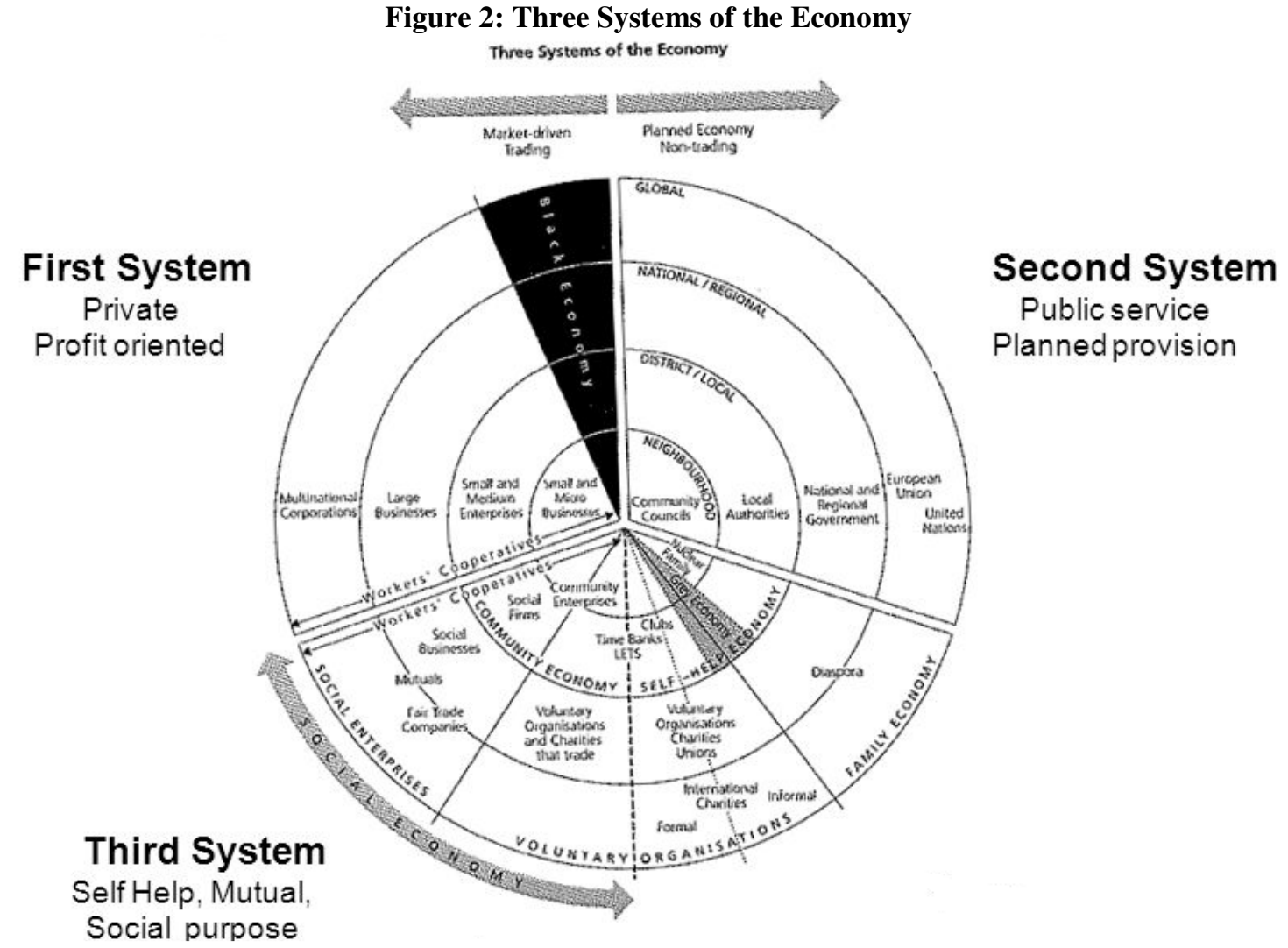

Source: Pearce (2003: 25)

The Three Systems model illustrates differences between the elements of the systems in different ways than Pestoff's the Wefare Mix model. The biggest difference is that Pearce introduces the notion of social purpose which unites family economy, voluntary organisations and social enterprises where Pestoff's model separates them on the grounds of formality/informality. In Pestoff's model, SEs would be 
intermediary organisations in the third sector, caught in between two distinct categories. In Pearce's model they occupy a space amongst other market driven traders but still within the third sector.

Pearce's system organises on the basis of the common values held by those that operate in either the first or third sector. The third sector being based on the '...principles of self-help and mutuality, caring for others and of meeting social needs...' (Pearce, 2003). Pearce argues against placing SEs as a subsector of the first economy as this would ignore the 'common value base...that binds it together as another way of doing things.' What is distinct about Pearce's orientation of SEs is that there is no 'blurred line' between SEs and traditional businesses. SEs and traditional businesses occupy adjacent space in a market driven trading economy but are differentiated on the basis of social purpose (Pearce, 2003).

Pearce's model is more detailed and includes family economy, voluntary organisations and SEs. Market driven trading (SEs) and non-trading aspects (family, economy and voluntary organisations) of the third sector are indicated e.g. the informal aspects within the private profit orientated system are identified as well as within the third sector. What the models have in common is the components included in the economic model and the equal, or significant weight given to the third sector in relation to the other parts of the economy.

Pearce (2003) describes these three economies as being fundamentally different but not mutually exclusive. The three systems exist together and one or other system will be dominant at any given point in time. The whole system is split between market driven trading and planned non-trading. The third economy is split down the middle with SEs on the market-driven trading side.

Figure 3 Social Enterprises at the crossroads of the cooperative and non-profit sectors

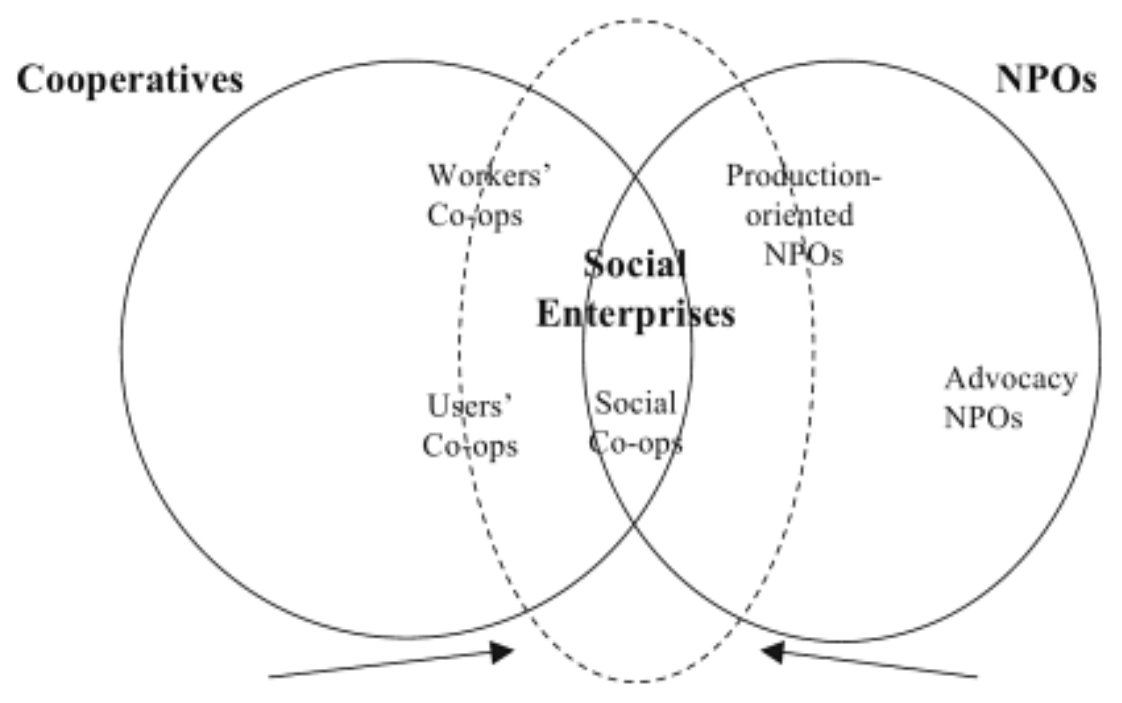

Source: Defourny (2014: 34)

With regard to positioning Defourny's (2014) contribution is also useful, in particular examining the third sector and its constituents. Defourny's discussion highlights the paradoxes that make SEs difficult to define. Within the social economy Defourny 
places SEs between non-profit organisations, operating outside the market and the cooperatives that operate in the market. SEs are in a space overlapping both and also with recognition of their ability to operate outside these spheres entirely (see figure 3 ).

Defourny recognises the roots of SEs as being in the third sector but also recognises the scope of their diversity. Private for-profit organisations may undertake to start SEs or support them as part of their corporate social responsibility projects. They may pursue shared value creation as part of their main business strategy (Porter, 2012). In some countries SEs may be closely linked to public bodies (Eastern Asia) in others state support is weak and SEs are more closely linked with the private for profit sector (see figure 4).

Figure 4 Social Enterprise at the cross roads of public policies, for-profit companies and the third sector

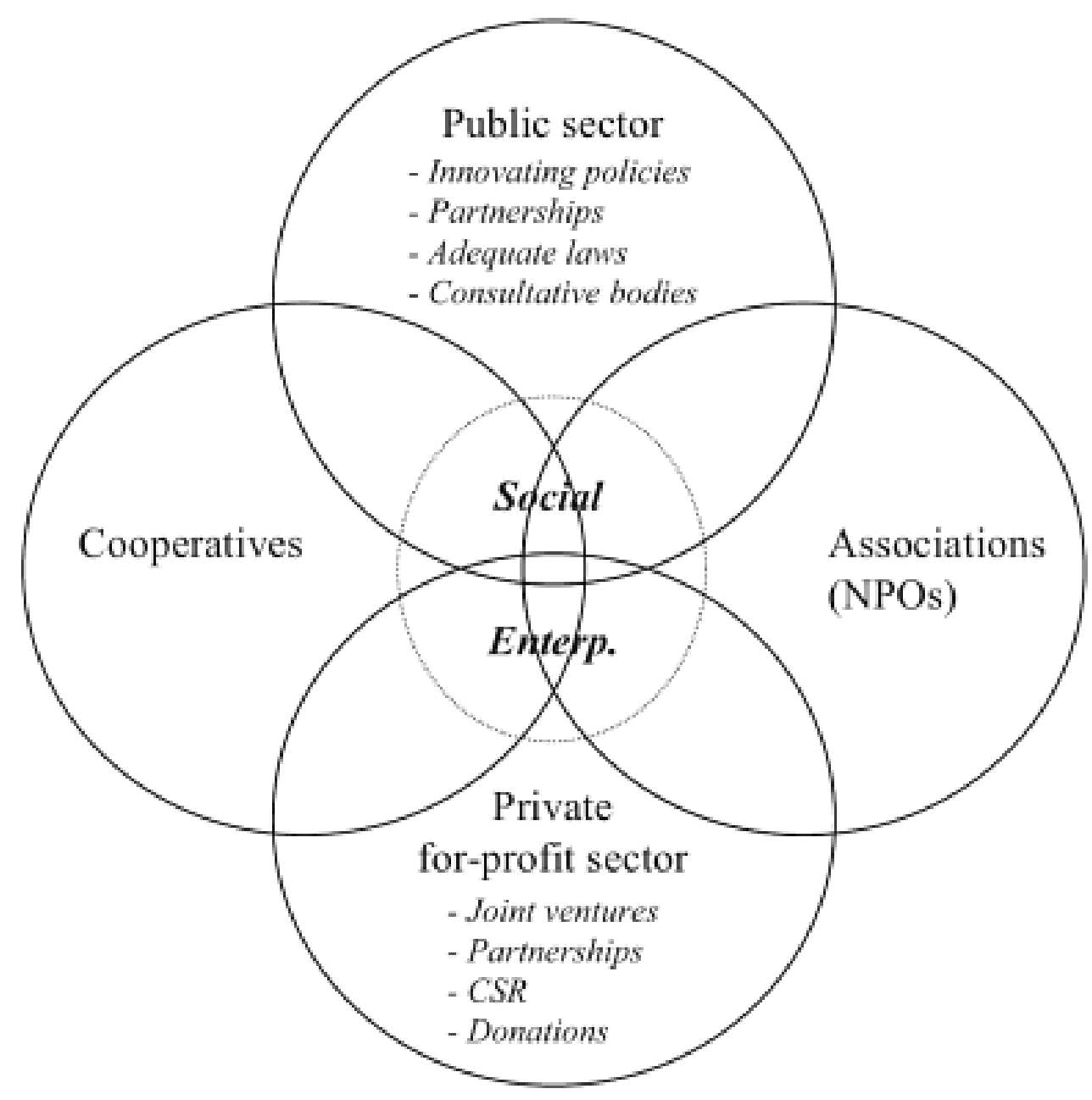

Defourny (2014: 36)

Defourny includes the blurred lines of SEs. This is in contrast to Pearce's positioning of SEs inside the third sector, on the basis of the 'values' underpinning each business. 
The differences in Pearce's and Defourny's models should be considered in view of the differences in their contribution to the field of social enterprise. Pearce's Three Systems of the Economy model offers a more utopian view of the SE which aligns them with what can be described as a new approach to capitalism. Pearce presents social enterprise as part of a third 'system' that can potentially dominate and preside over the private and public systems. Pearce's positioning of SEs as separate from the private sector on the basis of their values seeks to protect and maintain their place within the third sector rather than allow for blurred lines.

Defourny's contribution is based on empirical research bringing together what we know about SEs and using that knowledge to position them in the wider economic context. Defourny's models acknowledge the blurred lines between the SEs and the private and public sectors because that is what has been found (Defourny et al., 2014a). It seems Pearce's contribution is more evangelistic and Political than Defourny's although further consideration of Defourny's research would be needed to identify any apparent agenda.

The discussions of how to position SEs continue. Mikami (2014) compares public, private and non-profit organisations (specifically worker cooperatives and consumer cooperatives) solely on the basis of ownership and the right to control and the right to receive residual income. This approach ignores the objectives of the organisations being compared and takes a purely economic point of view. The discussion highlights potential differences amongst SEs and the similarities between certain types of SEs and commercial and public organisations. Mikami (2014) proposes that SEs do not necessarily require a separate category and are perhaps not distinct from for-profit or public organisations.

\section{Conclusion}

The following findings were made as a result of this review; there is not yet agreement on the definition for social enterprise, an accepted definition is desirable, there are multiple factors contributing to a failure for a consistent definition to emerge, the lack of clarity has led to challenges in the interpretation of research in the field and that it is necessary to understand the context of SEs to better understand these debates.

Time spent untangling the literature may not provide progress toward a definitive answer to the question 'what is a social enterprise?' but will inform selection of a definition for a particular purpose. This journey reveals much about the origins and context of SEs that provide a deeper understanding of the field.

For the purposes of further exploratory research in the field the EMES definition provides the most appropriate definition reflective of the research approach. Its use of 'desirable characteristics' makes it flexible but meaningful. Adopting this definition provides a framework by which to compare businesses without imposing boundaries where these may not be universally accepted.

International Journal of Management and Applied Research, 2015, Vol. 2, No. 2 
The researcher recommends further research to explore the perspectives of users, employees and managers of social enterprises to add to the discussion that already exists amongst the academics and policy makers. This approach would provide an opportunity to better understand the meaning, use and need for definitions of SE in practice, broaden our understanding of SEs and ensure that the discussion continues to be meaningful and based in real world research.

\section{References}

1. Borzaga, C. and Defourny, J. (2001), The Emergence of Social Enterprise, London: Routledge.

2. Bull, M and Crompton, H. (2006), "Business Practices in Social Enterprises", Social Enterprise Journal, Vol. 2, No. 1, pp.42-60. https://doi.org/10.1108/17508610680000712

3. Dart, R. (2004), "The Legitimacy of Social Enterprise", Non-profit Management and Leadership, Vol.14, No. 4. pp. 411-424. https://doi.org/10.1002/nml.43

4. Defourny, J., Hulgard, L. and Pestoff, V. (2014), "Introduction to the SE Field" in: Defourny, J., Hulgard, L. and Pestoff, V. (Ed), Social Enterprise and the Third Sector. New York: Routledge.

5. Defourny, J. (2014), "Chapter One: From Third Sector to Social Enterprise", in Defourny, J., Hulgard, L. and Pestoff, V. (Ed.), Social Enterprise and the Third Sector, New York: Routledge.

6. Defourny, J. and Kim. S.Y. (2011), "Emerging Models of Social Enterprise in Eastern Asia: a Cross-Country Analysis", Social Enterprise Journal. Vol. 7, No. 1, pp. https://doi.org/10.1108/17508611111130176

7. Defourny, J. and Nyssens, M. (2014), "The EMES Approach of Social Enterprise in a Comparative Perspective", in Defourny, J., Hulgard, L. and Pestoff, V. (Ed) Social Enterprise and the Third Sector, New York: Routledge.

8. Doherty, B., Foster, G., Mason, C., Meehan, J., Meehan, K. (2009), "Introduction to the Landscape of Social Enterprises", in: Management for Social Enterprise, London: Sage.

9. DTI (2002), Social Enterprise: a strategy for success, [Online] available from: http://www.nftmo.com/adapt/publisher.kc/TMO\%20Docs/original\%20doc\%20lib \%20docs/Supporting\%20Information/TMOs\%20and\%20the\%20Right\%20to\%20 Manage/Soc\%20ent\%20stratNComm_047.pdf \{ Accessed on 26 Sept 2015]

10. ECOTEC (2003), Guidance on Mapping Social Enterprise, [Online] available from: http://webarchive.nationalarchives.gov.uk/+/http:/www.dti.gov.uk/socialenterprise /pdfs/finalrep.pdf [Accessed on 13 Oct 2015].

11. EMES International Research Network. (2015), About US, [Online] available from: http://www.emes.net/about-us/who-we-are/ [Accessed on 13 Oct 2015]. 
12. European Social and Economic Committee, (2007), The Social Economy in Europe[Online] available from: http://www.eesc.europa.eu/resources/docs/eesc2007-11-en.pdf [Accessed on 13 Oct 2015].

13. Galera, G. and Borzaga, C. (2010), "Social Enterprise: An International Overview of its Conceptual Evolution and Legal Implementation", Social Enterprise Journal, Vol.5, No. 3, pp. 210-228. https://doi.org/10.1108/17508610911004313

14. Gordon, M. (2013), “The Development and Application of a Typology of Social Enterprise 'Traditions"', paper presented in 5th EMES International Research Conference on Social Enterprise. Liege 2013.

15. HM Treasury (1999), Enterprise and social exclusion, London: HM Treasury.

16. IFF Research ltd. (2005), A Survey of Social Enterprises Across the UK [Online] available from:

http://webarchive.nationalarchives.gov.uk/+/http:/www.cabinetoffice.gov.uk/medi a/cabinetoffice/third_sector/assets/survey_social_enterprise_across_uk.pdf [Accessed on 13 Oct 2015].

17. Jones, D and Keogh, B. (2006), "Social Enterprise: A Case of Terminological Ambiguity and Complexity", Social Enterprise Journal, Vol. 2, No. 1, pp.11-26. https://doi.org/10.1108/17508610680000710

18. Kerlin, J.A. (2010), “A Comparative analysis of the global emergence of social enterprise", Voluntas: International Journal of Voluntary and Nonprofit Organizations, Vol. 21, No. 2, pp. 162-179. https://doi.org/10.1007/s11266-0109126-8

19. Lyon, F., Teasdale. S and Baldock, R. (2010), Working Paper 43. Approaches to measuring the scale of the social enterprise sector in the UK, UK: Third Sector Research Centre.

20. Mikami, K. (2014), "An Alternative Framework for the Analysis of Social Enterprises", Journal of Co-operative Organization and Management, Vol. 2, No. 2, pp.92-97. https://doi.org/10.1016/j.jcom.2014.03.005

21. Pearce, J. (2003, Social Enterprise in Anytown, London: Calouste Gulbenkian Foundation.

22. Peattie, K. and Morley, A. (2008), "Eight paradoxes of the Social Enterprise Research Agenda", Social Enterprise Journal, Vol. 4, No. 2, pp. 91-107. https://doi.org/10.1108/17508610810901995

23. Peredo, A.M. and McLean, M. (2006), "Social Entrepreneurship: A Critical Review of the Concept", Journal of World Business, Vol.41, No. 1, pp. 56-65. https://doi.org/10.1016/j.jwb.2005.10.007

24. Pestoff, V. (1992), "Third Sector and Co-operative Services- An Alternative to Privatization", Journal of Consumer Policy, Vol.15, No. 1, pp.21-45. https://doi.org/10.1007/BF01016352

25. Porter, M.E. and Kramer, M.R. (2011), "Creating Shared Value: How to Reinvent Capitalism-and Unleash a Wave of Innovation Growth", Harvard Business Review, Vol. 89, No. 1/2, pp. 62-77 
26. Somers, A. (2013), The Emergence of Social Enterprise Policy in New Labour's Second Term, Doctoral thesis, Goldsmiths, University of London. [Thesis]: Goldsmiths Research [Online] Available at: http://research.gold.ac.uk/8051/. [Accessed on 23 June 2015].

27. Teasedale, S. (2010), "What's in a Name? The Construction of Social Enterprise", Paper presented to Public Administration Committee Conference, Nottingham Trent University, 8th September 2010.

28. Teasedale, S., Lyon, F. and Bladock, R. (2013), "Playing With Numbers: A methodological critique of the social enterprise myth", Journal of Social Entrepreneurship, Vol. 4, No. 2, pp. 113-131. https://doi.org/10.1080/19420676.2012.762800

29. Thompson, J. (2011), "Reflections on Social Enterprise and the Big Society", Social Enterprise Journal, Vol. 7, No. 3, pp.219-223. https://doi.org/10.1108/17508611111182377

30.Zahra, A.S., Rawhouser, H.N., Bhawe, N., Neubaum, Hayton, J. (2008) "Globalization of Social Enterprise Opportunities", Strategic Entrepreneurship Journal, Vol.2, No. 2, pp.117-131. https://doi.org/10.1002/sej.43 